\title{
Expression of the prostaglandin F synthase AKR1B1 and the prostaglandin transporter SLCO2A1 in human fetal membranes in relation to spontaneous term and preterm labor
}

\author{
Hana A. Alzamil', Joya Pawade ${ }^{2}$, Michel A. Fortier $^{3}$ and A. López Bernal ${ }^{4}$ \\ ${ }^{1}$ Department of Physiology, King Saud University, Riyadh, Saudi Arabia \\ 2 Pathology, University Hospitals Bristol Haemato-Oncology Diagnostic Service, Bristol Royal Infirmary, Bristol, UK \\ ${ }^{3}$ Axe Reproduction, Santé Périnatale et Pédiatrie, Centre Hospitalier Universitaire de Québec, Université Laval, QC, Canada \\ ${ }^{4}$ Academic Unit of Obstetrics and Gynaecology, School of Clinical Sciences, University of Bristol, Bristol, UK
}

Edited by:

Raheela N. Khan, University of

Nottingham, UK

Reviewed by:

Celena Scheede-Bergdahl, McGill

University, Canada

Neil Robert Chapman, University of

Sheffield, UK

*Correspondence:

A. López Bernal, Academic Unit of Obstetrics and Gynaecology, School of Clinical Sciences, University of Bristol, Dorothy Hodgkin Building, Whitson Street, Bristol, BS1 3NY, UK

e-mail: a.lopezbernal@bristol.ac.uk
Background: Human labor is a complex series of cellular and molecular events that occur at the materno-fetal and uterine levels. Many hypotheses have been proposed for the initiation of human labor, one hypothesis suggests that maturation of the fetus releases a signal in the amniotic fluid that will be transmitted to myometrium via the fetal membranes and initiate uterine contractions. There is strong evidence that prostaglandins (PGs) play a central role in initiation and progression of human labor.

Objectives: In this study we intended to investigate the expression of prostaglandin $\mathrm{F}$ synthase and the prostaglandin transporter in the human fetal membranes and to explore the relationship between cytokines and PGs in the mechanism of human labor.

Methods: We used fetal membranes obtained before labor at term and after spontaneous labor at term or preterm to identify the changes in prostaglandin F synthase (AKR1B1) and human prostaglandin transporter (SLCO2A1) proteins in relation to parturition. Using fetal membranes explants we tested the effect of cytokines (interleukin-1 and tumor necrosis factor alpha) on PG production and the concomitant changes in cyclooxygenase-2 (PTGS2), AKR1B1 and SLCO2A1 expression.

Results: Expression of PTGS2 and AKR1B1 was upregulated in the fetal membranes in association with term labor while SLCO2A 1 was downregulated with advancing gestation and during term labor. Before labor, IL-1 increased the expression of PTGS2, however during labor TNF upregulated PTGS2 and AKR1B1 proteins.

Conclusions: The prostaglandin F synthase AKR1B1 is upregulated while prostaglandin transporter is downregulated during term labor. The amnion is more responsive than choriodecidua to stimulation with pro-inflammatory cytokines. The mechanisms of term and preterm labor are different.

Keywords: prostaglandins, cytokines, placenta, parturition, preterm birth, uterus

\section{INTRODUCTION}

Labor is the result of strong uterine contractions that lead to expulsion of the fetus to the extrauterine environment. The incidence of preterm births is increasing and represents one of the most challenging clinical problems all over the world. In the United States the preterm birth rate increased from $9.5 \%$ in 1981 to $12.7 \%$ in 2005 ; the reported rates of preterm birth in other developed countries and Europe range from 5 to $9 \%$ (Goldenberg et al., 2008). At St Michael's Hospital in Bristol the incidence of preterm births is approximately $8 \%$ of all births (Yuan et al., 2010).

The trigger of the onset of human labor is still unknown, despite the impressive gains in clinical, physiological, and biochemical knowledge. Some studies suggest that there are several mechanisms for the onset of labor in women, such as paracrine/autocrine events, fetal hormonal changes and overlapping maternal/fetal factors (Weiss, 2000). Interaction between several pathways might be essential to initiate the process of labor and may include changes in estrogen and progesterone levels, elevation of corticotropin-releasing hormone (CRH), increased production of prostaglandins (PGs) and increased sensitivity of the uterus to oxytocin (Navitsky et al., 2000). However, it is not known whether labor is due to stimulation of uterine contraction or loss of inhibitory mechanisms that keep the uterus quiescent during pregnancy (Lopez Bernal et al., 1995). 
There is strong evidence that PGs play a central role in initiation and progression of human labor. Generally it is believed that the main sources for PGs found in the amniotic fluid are the fetal membranes and decidua (Gibb, 1998; Olson and Ammann, 2007). The maternal plasma level of PGF metabolites increases with the onset of labor at term as well as preterm (Sellers et al., 1981). Locally produced PGs can stimulate uterine contractions by: (1) direct effect via their own receptors in the myometrium (Senior et al., 1993), (2) increasing the sensitivity of the myometrium to oxytocin through upregulation of oxytocin receptors (OTR) (Chan and Chen, 1992), (3) upregulation of myometrial gap junctions (Ivanisevic et al., 2001). Oxytocin and PGs have a positive interaction which might be vital for coordinated and efficient uterine contraction at the time of labor (Arias, 2000).

The PGs biosynthesis cascade involves different steps. First, arachidonic acid (AA) is liberated from membrane phospholipids principally through cytosolic phospholipase $A_{2}$. AA is then converted into prostaglandin $\mathrm{H}_{2}\left(\mathrm{PGH}_{2}\right)$, a relatively unstable compound, by the action of prostaglandin $\mathrm{H}$ synthases (PTGS) also known as cyclooxygenase enzymes and then into bioactive PGs by terminal synthases such as TXA-, PGE-, and PGFsynthases. PTGS enzymes have received most of the attention in the literature; many studies have investigated their changes with labor and the effect of blocking their actions in the management of preterm labor (Fuentes et al., 1996; Slater et al., 1999; Johnson et al., 2002; Stika et al., 2002). Terminal synthase pathways beyond PTGS, other than PGE synthases, have not been well-investigated, although they might be excellent specific target in the prevention of preterm labor. There are three different pathways for the synthesis of the uterotonic $\mathrm{PGF}_{2 \alpha}$ : (1) from $\mathrm{PGH}_{2}$ by PGH 9-, 11-endoperoxide reductase, (2) from $\mathrm{PGD}_{2}$ by PGD 11-ketoreductase, (3) from $\mathrm{PGE}_{2}$ by PGE 9-ketoreductase (Watanabe, 2002).

The main source of $\mathrm{PGF}_{2 \alpha}$ is the direct conversion of $\mathrm{PGH}_{2}$ by $\mathrm{PGH}_{2}$ 9, 11-endoperoxide reductase; this activity is known as PGF synthase (Watanabe et al., 1985). Only small amounts of $\mathrm{PGF}_{2 \alpha}$ are produced through reduction of $\mathrm{PGE}_{2}$ by carbonyl reductase 1. AKR1B1 has recently been identified as a functional PGF synthase in the human uterus (Bresson et al., 2011) and based on its molecular weight, amino acid sequence and substrate specificity it has been assigned to the aldo-keto reductase family (Suzuki et al., 1999). Although $\mathrm{PGF}_{2 \alpha}$ is known to increase at the time of labor and proved to induce myometrial contractions, to date there is no information about PGF synthase expression and regulation in human fetal membranes during pregnancy and labor (Helliwell et al., 2004).

PGs are of lipid nature; however they diffuse poorly through plasma membranes because they exist as charged species at physiological pH (Schuster, 1998). The mechanism of PG transport across the plasma membrane is not well-known, however different models have been proposed such as simple diffusion, countercurrent transfer and carrier-mediated transport (Banu et al., 2005). A prostaglandin transporter (SLCO2A1) is broadly distributed in human tissues and it is likely that it has a role in clearance and metabolism of endogenous prostanoids (Lu et al., 1996). The functional uptake-carrier SLCO2A1 is a 12-transmembrane protein which has high affinity for $\mathrm{PGE}_{2}, \mathrm{PGF}_{2 \alpha}$, and $\mathrm{PGD}_{2}$. During the menstrual cycle the expression of SLCO2A1 in human endometrium was found to be modulated at mRNA and protein levels, (Kang et al., 2005). To date there is very little information regarding the distribution of prostaglandin $\mathrm{F}$ synthase (AKR1B1) and prostaglandin transporter (SLCO2A1) in the human fetal membranes in relation to term and preterm labor. AKR1B1 and SLCO2A1 are more abundant in choriodecidua than in the amnion (Breuiller-Fouche et al., 2010; Phillips et al., 2011).

Cytokines provide a major soluble intracellular signaling network which allows biochemical cross-talk between the fetus and the uterus. Moreover it has been proposed that regulation of prostaglandin production by pro-inflammatory cytokines is an important aspect of the mechanism of labor (Hansen et al., 1999). Paracrine and autocrine interactions between pro-inflammatory cytokines, especially interleukin-1 (IL-1) and tumor necrosis factor-alpha (TNF), and PGs have been demonstrated in term human decidua (Norwitz et al., 1992; Hansen et al., 1999). There is strong evidence that fetal membranes are involved in the process of human labor via release of PGs, however there are relatively few studies comparing PG production from membranes obtained before labor and those obtained after term and preterm labor.

The purpose of this manuscript was to examine the distribution of key enzymes for PG synthesis and transport in the fetal membranes/decidua interface and to look for differences in expression in relation to gestational age and the absence or presence of term and preterm labor. Moreover we intended to test the effect of IL-1 and TNF on PG release, using an ex-vivo fetal membranes model that preserves the anatomical integrity of the tissues. We have conducted detailed experiments on the expression of terminal PGF synthase and transporter in fetal membranes, and assessed the effect of pro-inflammatory cytokines on their protein expression levels. This study provides novel information on the source of triggers of human labor and the roles of inflammatory cytokines in the mechanism of parturition that will help in improving the management of preterm labor.

\section{MATERIALS AND METHODS COLLECTION OF TISSUES}

The study was approved by the North Somerset and South Bristol Research Ethics Committee. Placentas were collected from delivery suite in St Michael's Hospital, Bristol, after women were informed of the study and signed a consent form. All women had singleton gestations and experienced spontaneous labor at term (37-42 weeks gestation) or preterm (25-36 weeks), or had an elective cesarean section before any signs of labor at term. Patients admitted for elective preterm deliveries, due to placenta praevia or preeclampsia, or induction of labor (IOL) at term were also recruited (Table 1). The following groups of women were included: Term not in labor (TNIL), preterm not in labor (PNIL), spontaneous preterm labor (SPL), spontaneous term labor (STL), and IOL. Patients with multiple pregnancies, prolonged rupture of the membranes, or any signs of infection, including histological chorioamnionitis, were excluded. All tissues were carried to the laboratory in sterile cold saline and used immediately for tissue 
Table 1 | Clinical details of patients whose samples were used in this study.

\begin{tabular}{|c|c|c|c|c|c|}
\hline Mean (range) & TNIL & PNIL & SPL & STL & IOL \\
\hline Number $(n)$ & 7 & 9 & 8 & 9 & 9 \\
\hline Parity & $1(1-2)$ & 0 & $1(0-2)$ & $1(0-2)$ & 0 \\
\hline Gestational age (weeks +days) & $39(39-40)$ & $33^{+4}(27-36)$ & $32^{+2}(25-36)$ & $40(39-40)$ & $41^{+4}(39-42)$ \\
\hline Duration of labor (h:min) & - & - & $5: 21(1: 8-17: 7)$ & $7: 15(00: 20-11: 8)$ & $9: 26(6: 7-12: 44)$ \\
\hline Fetal weight (gm) & $3790(3300-4000)$ & $1719(585-2930)$ & 1674 (780-2100) & 3438 (2790-4000) & $3713(2870-4380)$ \\
\hline
\end{tabular}

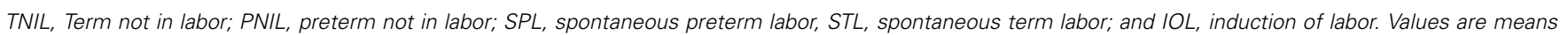
with ranges in brackets.

culture, fixed for immunochemistry, or snap frozen and stored in liquid nitrogen till used.

\section{MATERIALS}

Primary antibodies against AKR1B1 and SLCO2A1 were produced and characterized in house (Kang et al., 2005). PTGS2 antibodies were purchased from Santa Cruz Biotechnology (2145 Delaware Avenue Santa Cruz, CA, 95060 USA). RhoGDI was used as a reference given its strong expression in human intrauterine tissues (Lartey et al., 2006). Antibodies' species of origin, source, catalog number and dilutions for immunochemistry and immunoblotting are summarized in Table 2 .

The secondary antibodies used were horseradish peroxidase conjugated (DAKO, Ely, UK). The rabbit anti-goat was used at 1:1000 dilutions, swine anti-rabbit was used at 1: 1000 and the rabbit anti mouse at 1:200. Cytokines (IL-1 and TNF- $\alpha$, BioSource Europe, Belgium) were added to membranes in the explants to test their effects on PG production.

\section{IMMUNOHISTOCHEMISTRY}

Placental tissues were fixed with formalin for $24 \mathrm{~h}$. Representative blocks of each tissue were taken and processed in the Histopathology Department at the Bristol Royal Infirmary with a Leica JUNG TP 1050 Tissue processor (Leica, Heidelberg, Germany) into paraffin wax and sectioned at $2 \mu \mathrm{m}$ thickness.

The sections were dewaxed in Histo-Clear and passed through alcohol. Endogenous peroxidase activity was blocked by $1 \%$ hydrogen peroxide and then washed in running water. The antigen was retrieved by boiling in a microwave after immersion in $500 \mathrm{ml}$ of citrate buffer solution. After washing with PBS 0.02\% Tween, the slides were blocked in a solution containing $1 \%$ bovine serum albumin (BSA) plus 1\% normal human serum and left at room temperature for $1 \mathrm{~h}$.

The primary antibodies were prepared in PBS solution, added directly onto the sections and incubated overnight in a humid chamber at $4^{\circ} \mathrm{C}$, then washed in PBS $0.02 \%$ Tween-20 three times each for $5 \mathrm{~min}$. Secondary antibodies were added at room temperature for at least $1 \mathrm{~h}$, and then washed in the same way as the primary antibodies. The slides were incubated with DAB solution for $10 \mathrm{~min}$ after which were dipped in water and then counterstained with Mayer's hematoxylin for $30 \mathrm{~s}$ and washed with tap water. The slides were dehydrated in graded alcohol solutions and fixed in Histo-Clear, then mounted using mounting media and covered with coverslips. The primary antibodies were excluded
Table 2 | Source and dilutions of primary antibodies used in immunohistochemistry (IHC) and immunoblotting (IB).

\begin{tabular}{lllcc}
$\begin{array}{l}\text { Primary } \\
\text { antibody }\end{array}$ & Species & $\begin{array}{l}\text { Source } \\
\text { (Catalog umber) }\end{array}$ & $\begin{array}{c}\text { Dilution } \\
\text { (IHC) }\end{array}$ & $\begin{array}{c}\text { Dilution } \\
\text { (IB) }\end{array}$ \\
\hline AKR1B1 & Rabbit & Gift from Dr. Fortier & $1: 100$ & $1: 2000$ \\
hPGT & Rabbit & Gift from Dr. Fortier & $1: 50$ & $1: 1000$ \\
PGDH & Rabbit & Gift from Dr. Fortier & $1: 100$ & $1: 100$ \\
PGES & Rabbit & Cayman (160140) & $1: 50$ & $1: 1000$ \\
COX-2 & Goat & Santa Cruz (sc-1745) & $1: 50$ & $1: 250$ \\
RhoGDI & Goat & Santa Cruz (sc-360) & - & $1: 20000$ \\
\hline
\end{tabular}

during staining of the slides used as a negative control for the secondary antibodies.

Images were obtained by using a Leica DC300 camera (Leica, Heidelberg Germany) mounted on an Olympus BX40 microscope (Melville, NY, USA).

\section{IMMUNOBLOTTING}

The tissues were homogenized on ice with cold RIPA buffer (50 mM Tris $\mathrm{pH} 7.5,150 \mathrm{mM} \mathrm{NaCl}, 1 \mathrm{mM}$ EDTA, 1\% NP40, $0.5 \%$ Triton $\times 100$ and $1 \%$ SDS) then centrifuged for $40 \mathrm{~min}$ at $16,000 \times \mathrm{g}$ and $4^{\circ} \mathrm{C}$. The supernatant was collected and the protein concentration was determined by the bicinchoninic acid protein assay kit (Thermo Scientific, Rockford, IL, USA).

Homogenized samples ( $50 \mu$ g protein) were separated by SDSPAGE (12\% gel) and transferred onto Immobilon membranes (VWR international, Poole, UK). Membranes were blocked with WesternBreeze (Invitrogen) blocking buffer for $1 \mathrm{~h}$ at room temperature, and then incubated with diluted primary antibodies overnight at $4^{\circ} \mathrm{C}$. After washing, the membranes were incubated with horseradish peroxidase-conjugated secondary antibodies (swine anti-rabbit, was used at 1: 5000 dilution and rabbit antigoat at 1:20000) for $2 \mathrm{~h}$ at room temperature. Membranes were then washed (three times for $5 \mathrm{~min}$ ) with washing buffer and prepared for detection by chemiluminescence (Immobilon Western Chemiluminescent HRP Substrate, Millipore, Billerica, MA, US). PTGS2 protein was recognized by its antibody at $72 \mathrm{kDa}$ whereas AKR1B1 protein was recognized by the antibody at $37 \mathrm{kDa}$ and SLCO2A1 protein at $72 \mathrm{kDa}$. All detected bands were normalized to their individual RhoGDI bands, and then normalized to the ratio of PTGS2 to RhoGDI of a pooled sample used in all gels to eliminate the variations among different gels. 


\section{FETAL MEMBRANE EXPLANTS}

Membranes were manually cut into discs (18 $\mathrm{mm}$ in diameter) and were held using silicone rubber rings in the upper chamber of a Transwell system (Costar) in which the original disc had been removed. In this model the choriodecidua faces the upper chamber, and the amnion faces the lower chamber. The mounted explant was then placed in a 12-well tissue-culture plate (Costar) (Zaga-Clavellina et al., 2007).

One milliliter of sterile Dulbecco's modified Eagle's medium (DMEM) supplemented with $10 \%$ fetal calf serum and antibiotic-antimycotic solution (penicillin, $100 \mathrm{U} / \mathrm{ml}$; streptomycin, $100 \mu \mathrm{g} / \mathrm{ml}$; amphotericin B, $0.25 \mu \mathrm{g} / \mathrm{ml}$ ) was added to each chamber. The plates were incubated under $5 \% \mathrm{CO}_{2}$ in $95 \%$ air at $37^{\circ} \mathrm{C}$ for $24 \mathrm{~h}$ to stabilize the tissues after manipulation.

\section{CYTOKINE EXPOSURE IN EXPLANTS AND MEASUREMENT OF PGE2 AND PGF $_{2 \alpha}$}

Pro-inflammatory cytokines stimulate prostaglandin synthase expression and PG release in human intrauterine tissues and we wished to examine the effect of cytokine exposure on both the maternal and fetal side of the fetal membranes on the rate of $\mathrm{PGE}_{2}$ and $\mathrm{PGF}_{2 \alpha}$ production (Norwitz et al., 1992; Phillips et al., 2011). The medium was changed to serum free DMEM, then explants were exposed to $10 \mathrm{ng} / \mathrm{ml}$ of IL- $1 \beta$, or TNF. We tested different doses and we found that $10 \mathrm{ng} / \mathrm{ml}$ of IL- $1 \beta$, or TNF were the appropriate doses that gave maximum stimulation without toxic effect on tissues. Each experiment included the following four conditions in duplicate for each membrane: (1) control membranes in which only medium was added to both compartments, (2) IL-1 $\beta$, or TNF added to upper compartment (choriodecidua) only, (3) IL-1 $\beta$, or TNF added to lower compartment (amnion) only, (4) IL-1 $\beta$, or TNF added to both upper and lower compartments simultaneously. The media on both sides were collected after $6 \mathrm{~h}$ of stimulation and frozen at $-80^{\circ} \mathrm{C}$ for prostaglandin assays. $\mathrm{PGE}_{2}$ and $\mathrm{PGF}_{2 \alpha}$ were measured in collected media using the ELISA technique. Incubation of the tissues for longer than $6 \mathrm{~h}$ did not show a further significant increase in prostaglandin production.

\section{ENZYME LINKED IMMUNOSORBENT ASSAY (ELISA) OF PROSTAGLANDINS}

Measurement of $\mathrm{PGE}_{2}$ and $\mathrm{PGF}_{2 \alpha}$ was performed using an ELISA technique in which acetylcholinesterase-linked PG tracers were used as described previously (Asselin et al., 1996). Rabbit anti$\mathrm{PGE}_{2}$ (kindly provided by Dr. T. G. Kennedy, University of Western Ontario, Ontario, ON, Canada) and sheep anti-PGF $2 \alpha$ (BioQuant, Ann Arbor, MI, USA) were used as selective antibodies. The inter- and intra-assay coefficients of variation $(n=12)$ were 16 and $10 \%$, respectively. Briefly, $50 \mu \mathrm{l}$ of collected culture medium was placed in a 96-well plate coated with goat anti-rabbit $\left(\mathrm{PGE}_{2}\right)$ or rabbit anti-sheep $\left(\mathrm{PGF}_{2 \alpha}\right)$ secondary antibody. A volume of $50 \mu \mathrm{l}$ from each the tracer and the respective primary antibody was added to each sample after which the samples were incubated overnight at room temperature. After washing each well, $200 \mu \mathrm{l}$ of Ellman's reagent $(69 \mathrm{mM}$ acetylthiocholine iodide;

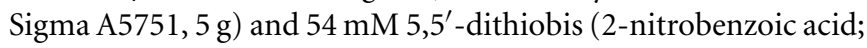
Sigma D8130, $5 \mathrm{~g}$ ) dissolved in $10 \mathrm{mM}$ phosphate buffer $\mathrm{pH} 7.4$ was added. The plate was incubated on a shaker in the dark at room temperature, the reactions between the bound enzyme tracer and the Ellman's reagent yield a yellow color that can be measured with a photometric plate reader. A standard curve was used ranging from 39 to $5000 \mathrm{pg} / \mathrm{ml} \mathrm{PG}$.

\section{STATISTICAL METHODS}

The data was analyzed with SAS statistical software version 9.1.3. (SAS Institute Inc., Cary, NC, USA). The groups were analyzed separately, using Two-Way ANOVAs for each group. Pairwise comparisons were made between the control mean and each of the 9 treatment means; multiple comparisons were calculated using Dunnett's procedure.

\section{RESULTS \\ LOCALIZATION OF PGF SYNTHASE AND PG TRANSPORTER IN INTRAUTERINE TISSUES AT TERM}

AKR1B1 and SLCO2A1 proteins were clearly expressed in decidual cells (Figures 1A-L). In decidual cytoplasm there was uneven distribution of AKR1B1 protein (Figure 1A) while the surrounding connective tissue appeared negative (Figure 1D). AKR1B1 protein was identified in the chorionic villi, in which the staining was strong in the cytoplasm of syncytiotrophoblasts while cytotrophoblasts and villous stroma were negative (Figure 1E). The SLCO2A1 protein was localized in decidual cytoplasm with no staining in the connective tissue (Figure 1G). The syncytiotrophoblasts in the chorionic villi showed weak staining in their cytoplasm and the cytotrophoblasts did not show any staining with SLCO2A1 antibodies (Figure 1H).

Staining with PTGS2 antibody was found to be strongly positive in the cytoplasm of some large decidual cells while smaller cells showed weak staining; connective tissue of decidua basalis showed no staining (Figure 1J). In the villi PTGS2 protein was localized in the cytoplasm, in the outer layer (syncytiotrophoblast) staining was intense, while the inner layer of the villi (cytotrophoblast) showed weak staining. Less intense staining was observed in the core of the villi (Figure 1K).

In the fetal membranes AKR1B1 was highly expressed in the chorion compared to decidua and there was no expression of this protein in the amnion while a poor staining was detected in the mesenchymal layer of the amnion (Figure 1F). The intensity of the staining with SLCO2A1 antibody was equal in the two layers of the fetal membranes and decidua parietals (Figure 1I).

All layers of the membranes and decidua parietals stained strongly positive with PTGS2 antibody, the staining was also observed in the mesenchymal layer of the amnion (Figure 1L).

\section{EFFECT OF LABOR ON THE EXPRESSION OF PGF SYNTHASE AND PG TRANSPORTER IN THE FETAL MEMBRANES}

Using immunoblotting we found an increase in the expression of AKR1B1 protein in fetal membranes collected after term labor whether spontaneous or induced. However, preterm labor was not associated with an increase in the level of AKR1B1 protein (Figure 2). By contrast, SLCO2A1 protein was significantly decreased with advancing gestation with no changes in association with labor at term or preterm (Figure 2). The increase in AKR1B1 in the STL group and the apparent decrease in SPL 

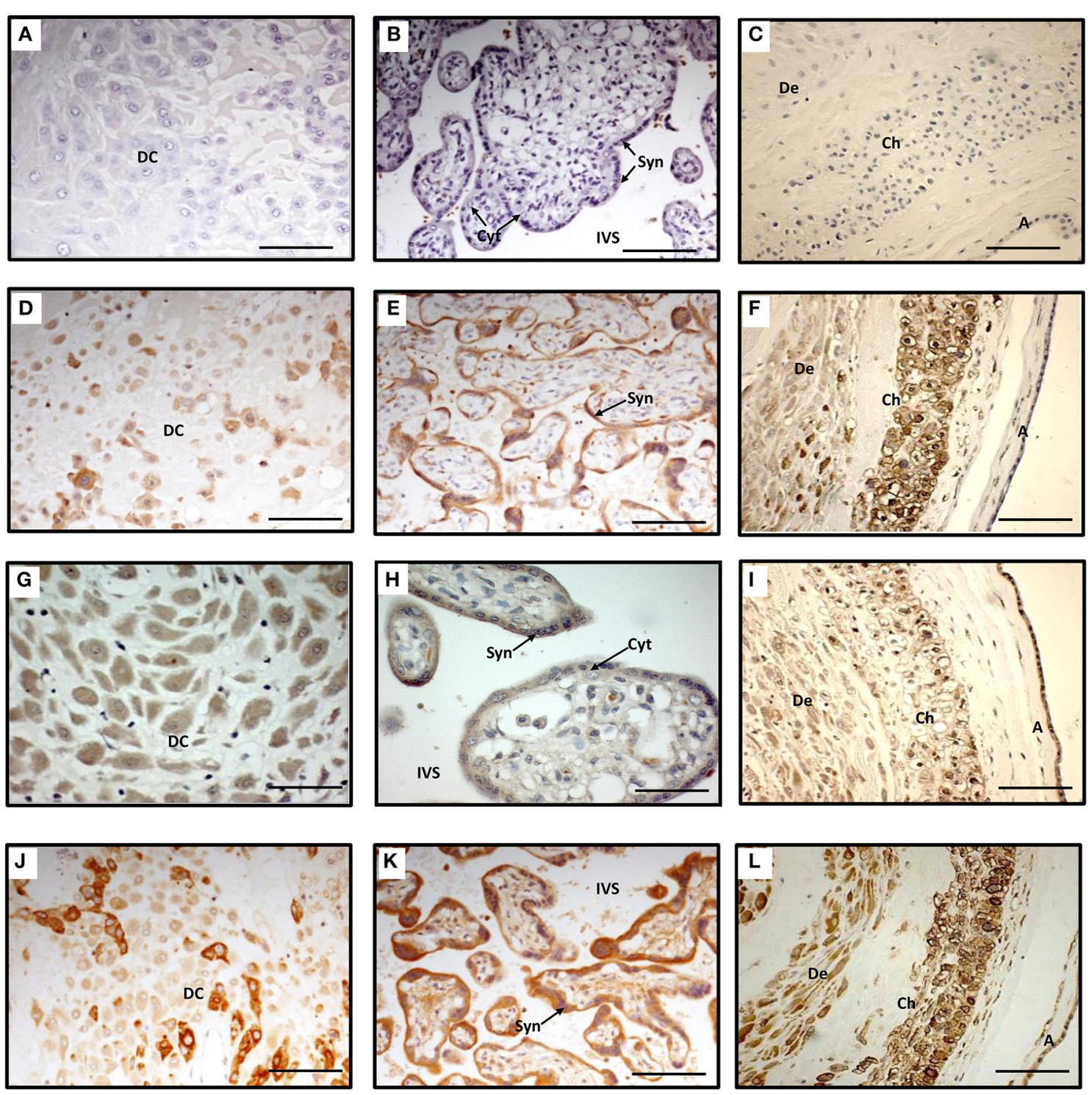

FIGURE 1 | Immunohistochemistry staining of term decidua basalis (A), chorionic villi (B) and fetal membranes (C) with AKR1B1 antibody (D-F), SLCO2A1 antibody (G-I), and PTGS2 antibody (J-L). Primary antibodies were omitted in (A-C) which served as controls. DC, decidual cells; Syn, syncytiotrophoblast; Cyt, cytotrophoblast; IVS, intervillous space; De, decidua parietalis; Ch, chorion; and A, amnion. Bar $=100 \mu \mathrm{m}$. reflected similar changes in PTGS2 protein expression in the same samples (data not shown).

\section{EFFECT OF CYTOKINES ON PG PRODUCTION IN THE FETAL MEMBRANES}

Exposure of the fetal side to IL- $1 \beta$ in all our tissues significantly increased $\mathrm{PGF}_{2 \alpha}$ and $\mathrm{PGE}_{2}$ production from the fetal side (Figure 3) and this was associated with a significant increase in PTGS2 protein expression. At term, before the onset of labor, TNF had a significant stimulatory effect on $\mathrm{PGF}_{2 \alpha}$ production from the fetal side when added to both sides of the membrane at the same time. This effect was associated with a significant increase in AKR1B1 expression in the TNIL group, but not in the STL and SPL groups (Figure 4).

\section{DISCUSSION}

To our knowledge this is the first study to compare the level of protein expression of the PGF synthase AKR1B1 and the PG transporter SLCO2A1 in fetal membranes of nonlaboring and laboring women at term and preterm. We have found that expression of PTGS2 and AKR1B1 is increased in fetal membranes at term labor, whereas SLCO2A1 decreases with advancing gestation and term labor. Prior to labor, IL-1 enhances the expression of PTGS2; while in labor TNF stimulates the expression of PTGS2 and AKR1B1. During term labor AKR1B1 is upregulated with a concurrent downregulation of the prostaglandin transporter SLCO2A1. IL-1 and TNF have a stronger stimulatory effect on PG release in the amnion than in choriodecidua. 


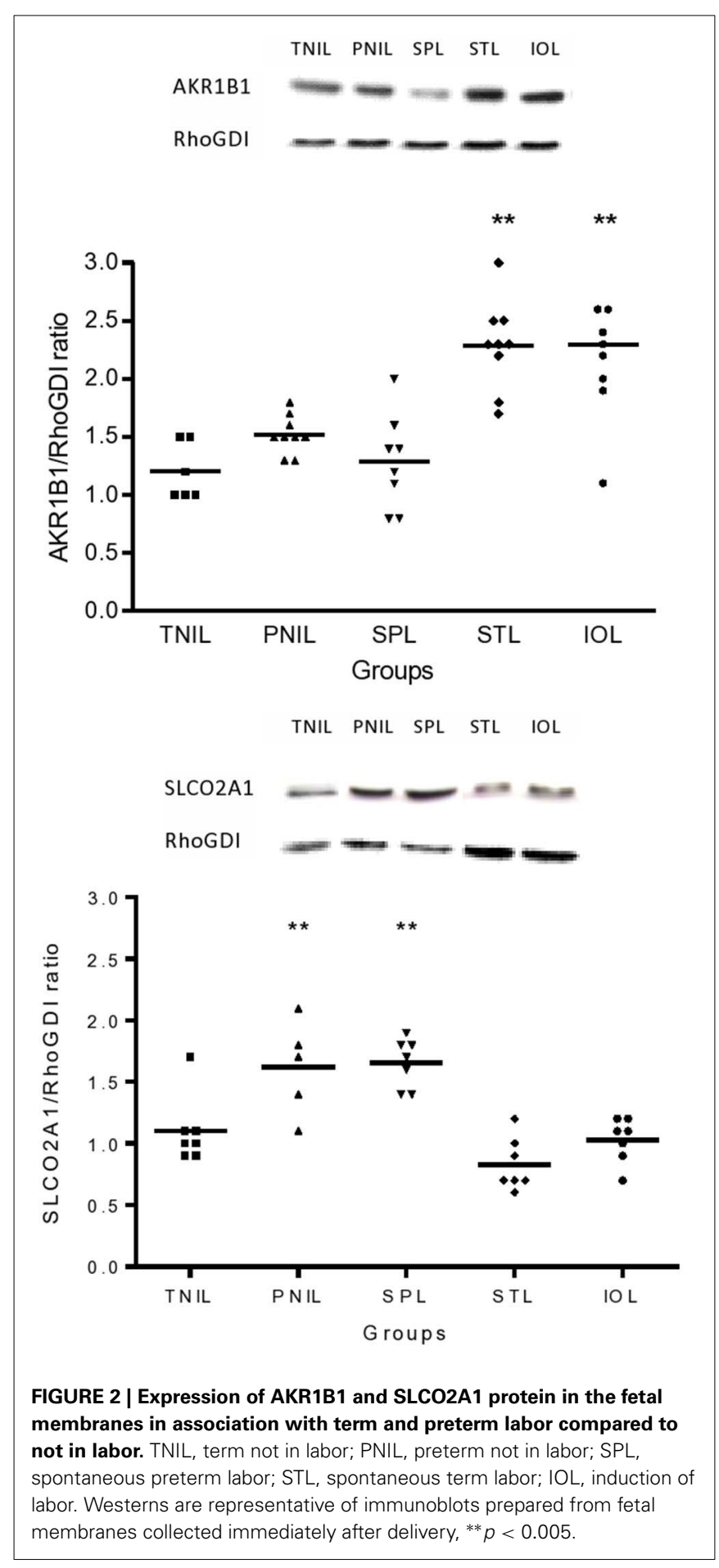

The fetal membranes are in close contact with the uterine decidua in an area estimated to be around $2000 \mathrm{~cm}^{2}$ and they are thought to have a central role in the process of human labor through paracrine effects on uterine activation (Myatt and Sun, 2010; Prince et al., 2014). It has been suggested that fetal membranes play a part in maintaining uterine quiescence by releasing putative inhibitors of spontaneous and oxytocin-induced uterine contractions (Carvajal et al., 2006). Any disturbance of

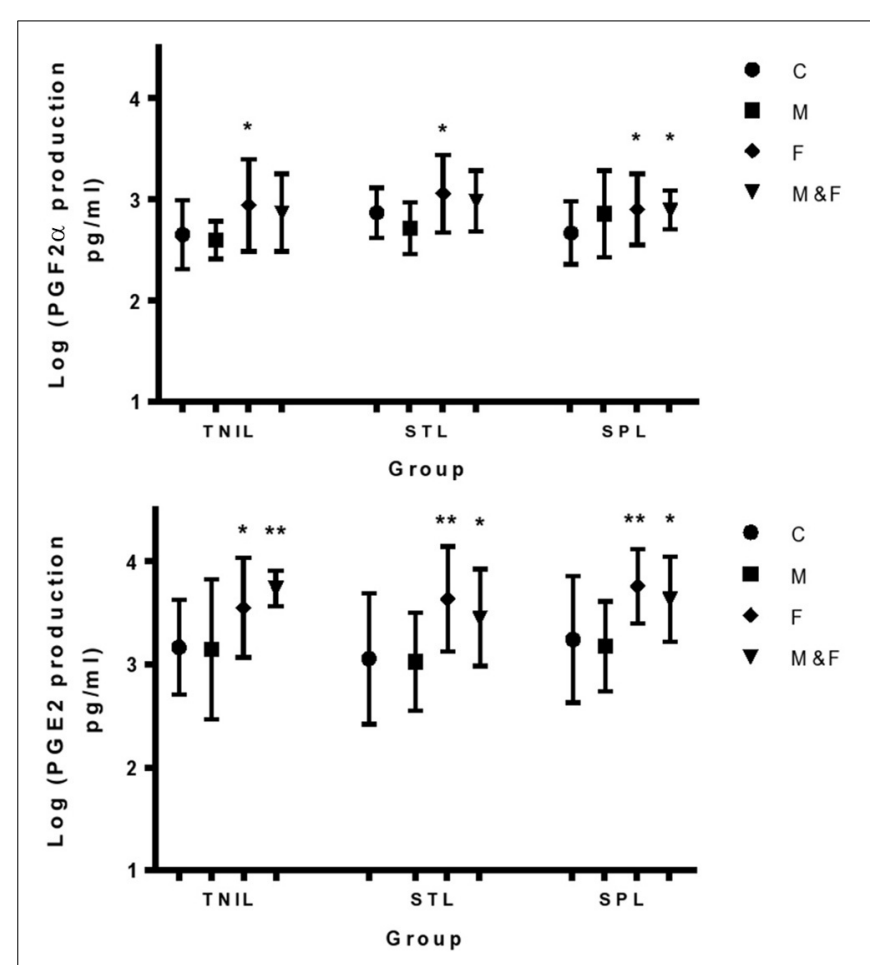

FIGURE 3 | Effect of IL-1 $\beta$ on $\mathrm{PGE}_{\mathbf{2}}$ and $\mathrm{PGF}_{2 \alpha}$ production from the fetal side of membranes. $C$, control; $M$, maternal side exposure; $F$, fetal side exposure; and M\&F, exposure to maternal and fetal sides; TNIL, term not in labor; STL, spontaneous term labor; SPL, spontaneous preterm labor. The bars represent the mean $\pm S D ; n=4, * p<0.05$ and ${ }^{* *} p<0.005$.

membrane integrity by amniotomy or membrane sweeping is known to be associated with a rapid increase in prostaglandin production followed by initiation of labor (Mitchell et al., 1977). Recently it has been proposed that the fetal membranes are involved in a positive feedback loop that stimulates the release of biologically active glucocorticoids and PGs which eventually lead to maturation of fetal organs and initiation of labor (Myatt and Sun, 2010).

In this paper we have described the localization of the proteins involved in $\mathrm{PGF}_{2 \alpha}$ synthesis and transport in intrauterine tissues. Our findings show that in fetal membranes PTGS2 protein is highly expressed in the amnion, chorion and adjacent decidua while AKR1B1 expression is highest in the chorion and is absent in the amnion. The co-localization of PTGS2 and AKR1B1 in the chorion and adjacent decidua indicate that $\mathrm{PGF}_{2 \alpha}$ production at this site is important for initiation of human labor. In addition we have demonstrated that SLCO2A1 protein is expressed in the amnion and chorion as well as the decidua. Our observations are in line with a recent study which confirmed that human fetal membranes possess autoregulatory mechanisms for $\mathrm{PGF}_{2 \alpha}$ action (Breuiller-Fouche et al., 2010). The same study reported that in both layers of the fetal membranes the expression of AKR1B1 was higher than that of another PGF synthase, namely AKR1C3 (Breuiller-Fouche et al., 2010).

The current study shows increased density of AKR1B1 protein in fetal membranes with term labor and a decrease of SLCO2A1 


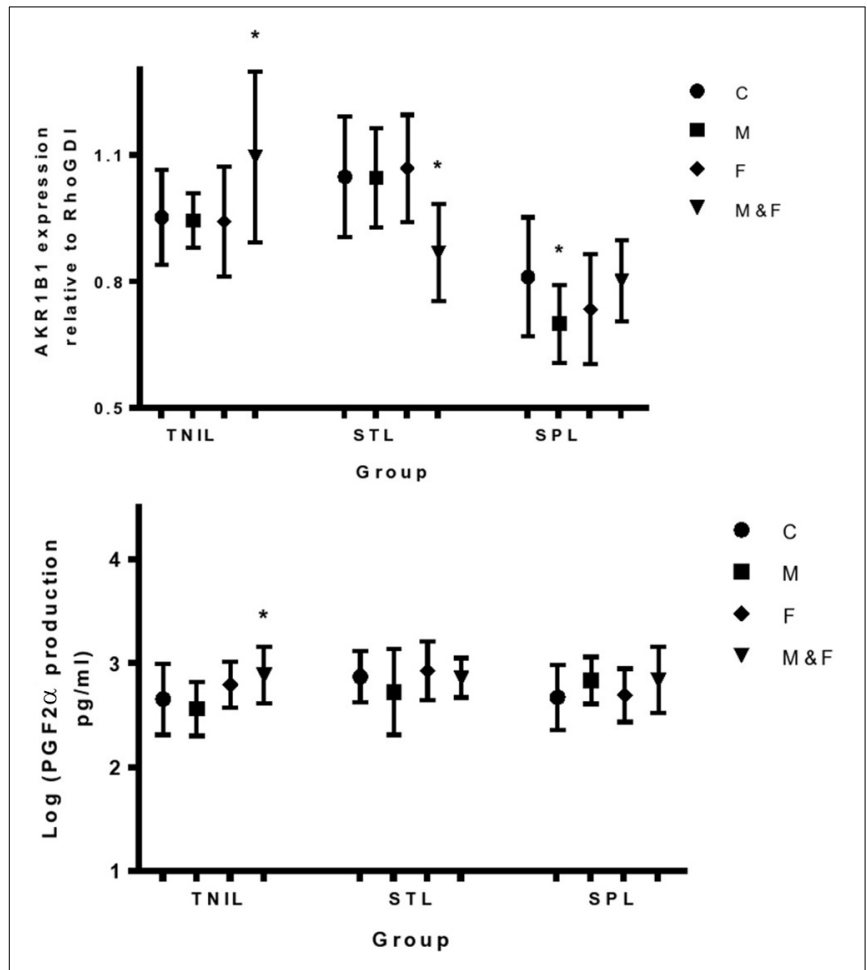

FIGURE 4 | Effect of TNF- $\alpha$ on expression of AKR1B1 protein in the fetal membranes and the associated changes in PGF $_{2 \alpha}$ production from fetal side of membranes. $C$, control; $M$, maternal side exposure; $F$, fetal side exposure; and M\&F, maternal and fetal sides exposure. TNIL, term not in labor; STL, spontaneous term labor; SPL, spontaneous preterm labor. The bars represent the mean $\pm \mathrm{SD} ; n=4{ }^{*} p<0.05$.

protein with advancing gestation. SLCO2A1 contributes to the uptake of PG by the cells for their degradation and clearance (Kang et al., 2006) and its downregulation can lead to accumulation of PGs at their site of action. The downregulation of SLCO2A1 expression combined with upregulation of AKR1B1 protein in fetal membranes could have a synergetic effect to increase the levels of local $\mathrm{PGF}_{2 \alpha}$ during term labor. Compared to the recent findings of low expression of AKR1B1 in human myometrium (Phillips et al., 2011) our study demonstrates that AKR1B1 is highly expressed in the fetal membranes especially in association with term labor. Recently it has been suggested that AKR1B1 may act as a multifunctional enzyme in the fetal membranes through mediating inactivation of progesterone besides generation of $\mathrm{PGF}_{2 \alpha}$ (Breuiller-Fouche et al., 2010).

Our findings have shown an increase in AKR1B1 in fetal membranes after IOL which suggests that this change is part of the final steps in the process of labor at term. However, preterm labor occurs with low levels of AKR1B1; this may reflect differences in gestational maturity of the fetal membranes and increased sensitivity of the myometrium to potential triggers of labor such as PGF2 $\alpha$. We have also observed that PTGS2 protein expression was significantly increased in fetal membranes in association with term but not preterm labor, which supports the assumption that the mechanism of spontaneous labor is at least partially different in term and preterm groups.
Late pregnancy is a complex equilibrium between physiological pathways that maintain uterine quiescence and potential disruption by inflammatory pathways probably triggered by infection although many questions remain (Prince et al., 2014). IL- 1 and TNF are key mediators of inflammation and immune responses and their potential role in labor has been emphasized earlier (Norwitz et al., 1992; Hansen et al., 1999). We have confirmed that IL- $1 \beta$ stimulates PGF $2 \alpha$ and PGE2 production from fetal membranes before and after the onset of labor; this implies that IL-1 $\beta$ is an important factor for initiation as well as establishment of human parturition. A recent study reported that the increase in production of PGF $2 \alpha$ and PGE2 after stimulation of human endometrial cells with IL- $1 \beta$ can be reduced in the presence of FP receptor antagonists, indicating that PGF $2 \alpha$ was able to stimulate its own and PGE2 productions (Bresson et al., 2012). Other workers found that IL-1 $\beta$ was a potent stimulator of PGE2 production from term intact fetal membranes collected before the onset of labor (Brown et al., 1998). Previous studies reported that IL-1 $\beta$ increased in the amniotic fluid of spontaneous term (Romero et al., 1992) as well as preterm labor (Baud et al., 1999). Another group of investigators reported that IL-1 $\beta$ increased oxytocin release from human decidua by a mechanism that involved production of PGs through PTGS2 upregulation (Friebe-Hoffmann et al., 2007). This local interaction between PGs and oxytocin may facilitate the progress of labor.

We have observed a moderate effect of TNF to initiate term labor through upregulation of AKR1B1 and stimulation of PGF2 $\alpha$ production. In line with our results, Sadowsky and colleagues, using intra-amniotic infusions of pro-inflammatory cytokines demonstrated that IL- $1 \beta$ was more effective than TNF in initiating preterm labor in rhesus monkeys (Sadowsky et al., 2006). Surprisingly, we observed that TNF inhibits AKR1B1 protein expression in membranes collected after labor when added to both sides in term and maternal side in preterm. This inhibition might be an important mechanism to control the level of PGF2 $\alpha$ during labor since high levels of PGF $2 \alpha$ might be harmful to the fetus if it triggered tetanic contractions.

Interestingly, in the current study we noticed that although the exposure of the fetal side of term fetal membranes to IL- $1 \beta$ stimulated PGF $2 \alpha$ production, the simultaneous exposure of fetal and maternal sides to IL- $1 \beta$ had no effect. Osman and coworkers reported that although the expression of IL- $1 \beta$ mRNA did not change in the choriodecidua (maternal side), its level was found to be significantly higher in the amnion (fetal side) after the onset of term labor (Osman et al., 2003). By contrast, the exposure of preterm membranes to IL- $1 \beta$ from both sides had an accumulating stimulatory effect for PGF $2 \alpha$ production providing further evidence for different mechanisms for term and preterm labor.

We observed that during term and preterm labor the amnion became more responsive to the stimulatory effect of IL-1 $\beta$ and released high levels of PGE2 when compared to not in labor membranes. This observation might indicate that the process of term and preterm labor involves upregulation of IL- $1 \beta$ receptors in the amnion.

Our findings suggest that the sequence of IL-1 $\beta$ effects in the fetal membranes is to stimulate PTGS2 expression by autocrine or paracrine action in choriodecidua, followed by paracrine 
stimulation of PG release in the amnion. In this regard Zaga and coworkers reported that IL- $1 \beta$ secretion to the amniotic compartment was observed only when choriodecidua and amnion were together. On the other hand when both tissues were mechanically separated, only choriodecidua secreted IL-1 $\beta$ (Zaga et al., 2004).

A previous study demonstrated that PTGS2 mRNA progressively accumulates in the membranes before and during labor causing a steady rise in PG biosynthetic capacity when translated into active protein (Johnson et al., 2002). Our findings imply that IL- $1 \beta$ released by fetal tissues, might be one of the factors that can stimulate PTGS2 expression via its action on the amnion. On the other hand, concurrent exposure of maternal and fetal sides of the membrane to TNF upregulated AKR1B1 protein in the membranes of non-laboring women, which explains the stimulatory effect of this cytokine on $\mathrm{PGF}_{2 \alpha}$ production.

The data in the current study support the hypothesis that fetal membranes, through their response to stimulation by proinflammatory cytokines and release of PGs, play an important role in the process of human labor. Pro-inflammatory cytokines released by fetal tissues could be important triggering factors that need to receive focused attention in future research in an attempt to find more effective targets for the management of preterm labor.

In conclusion, advancing gestation is associated with accumulation of PTGS2 protein as well as a decrease of SLCO2A1 protein that helps to prepare the fetal membranes to respond to stimulatory factor(s) in labor. TNF acts during labor to increase AKR1B1 protein level leading to increased $\mathrm{PGF}_{2 \alpha}$ production. We can speculate that the trigger of labor is probably coming from the fetal side of the membranes when IL- $1 \beta$ is released and leads to synthesis of PTGS2 protein which starts labor by increasing PG production. Increased $\mathrm{PGE}_{2}$ and $\mathrm{PGF}_{2 \alpha}$ production as reflected by rising amniotic fluid concentrations may promote membrane rupture and initiate uterine contractions.

Parturition must be the result of maturational events in the fetus, probably involving the hypothalamic pituitary adrenal axis, increased sensitivity of the uterus to stimulatory agonists and loss of inhibitory mechanisms in myometrial smooth muscle (Lopez Bernal et al., 1995; Li et al., 2014). In a minority of cases inflammatory infiltration of the fetal membranes and decidua may trigger premature labor, however many women go into preterm labor without signs of infection or inflammation and other mechanisms may be involved. In this regard it is interesting to note that oxytocin stimulates PTGS2 expression through a calcium dependent NFAT (nuclear factor of activated T cells) signaling pathway (Pont et al., 2012). Our findings also indicate that the mechanisms of spontaneous labor are different at term and preterm. Further research into the paracrine and autocrine effects of cytokines and PGs in the decidua/fetal membranes area is required to elucidate the biochemical and physiological events underlying these mechanisms.

\section{AUTHOR CONTIBUTIONS}

Hana A. Alzamil and A. López Bernal designed the protocols. H. Alzamil conducted the studies, data analyses and drafted the manuscript. A. López Bernal interpreted the data, revised and modified the draft critically. Joya Pawade interpreted the immunohistochemical data. Michel A. Fortier revised the draft critically. All authors approved the version to be published.

\section{FUNDING}

Hana A. Alzamil was supported by a Fellowship from King Saud University and the results were incorporated into a $\mathrm{PhD}$ thesis at the University of Bristol. The work was supported by Wellbeing of Women (grant RG825).

\section{ACKNOWLEDGMENTS}

We are grateful to Dr. Linda Hunt for statistical advice and data analysis and to research midwives Anne Duffner and Alison Kirby for obtaining consent from women at St Michael's Hospital and organizing the collection of samples.

\section{REFERENCES}

Arias, F. (2000). Pharmacology of oxytocin and prostaglandins. Clin. Obstet. Gynecol. 43, 455-468. doi: 10.1097/00003081-200009000-00006

Asselin, E., Goff, A. K., Bergeron, H., and Fortier, M. A. (1996). Influence of sex steroids on the production of prostaglandins F2 alpha and E2 and response to oxytocin in cultured epithelial and stromal cells of the bovine endometrium. Biol. Reprod. 54, 371-379.

Banu, S. K., Arosh, J. A., Chapdelaine, P., and Fortier, M. A. (2005). Expression of prostaglandin transporter in the bovine uterus and fetal membranes during pregnancy. Biol. Reprod. 3, 230-236. doi: 10.1095/biolreprod.105.039925

Baud, V., Liu, Z. G., Bennett, B., Suzuki, N., Xia, Y., and Karin, M. (1999). Signaling by proinflammatory cytokines: oligomerization of TRAF2 and TRAF6 is sufficient for JNK and IKK activation and target gene induction via an amino-terminal effector domain. Genes Dev. 13, 1297-1308.

Bresson, E., Boucher-Kovalik, S., Chapdelaine, P., Madore, E., Harvey, N., Laberge, P. Y., et al. (2011). The human aldose reductase AKR1B1 qualifies as the primary prostaglandin F synthase in the endometrium. J. Clin. Endocrinol. Metab. 96, 210-219. doi: 10.1210/jc.2010-1589

Bresson, E., Lacroix-Pepin, N., Boucher-Kovalik, S., Chapdelaine, P., and Fortier, M. A. (2012). The prostaglandin F synthase activity of the human aldose reductase AKR1B1 brings new lenses to look at pathologic conditions. Front. Pharmacol. 3:98. doi: 10.3389/fphar.2012.00098

Breuiller-Fouche, M., Leroy, M. J., Dubois, O., Reinaud, P., Chissey, A., Qi, H., et al. (2010). Differential expression of the enzymatic system controlling synthesis, metabolism, and transport of PGF2 alpha in human fetal membranes. Biol. Reprod. 83, 155-162. doi: 10.1095/biolreprod.109.080390

Brown, N. L., Alvi, S. A., Elder, M. G., Bennett, P. R., and Sullivan, M. H. (1998). Regulation of prostaglandin production in intact fetal membranes by interleukin-1 and its receptor antagonist. J. Endocrinol. 159, 519-526.

Carvajal, J. A., Vidal, R. J., Cuello, M. A., Poblete, J. A., and Weiner, C. P. (2006). Mechanisms of paracrine regulation by fetal membranes of human uterine quiescence. J. Soc. Gynecol. Investig. 13, 343-349. doi: 10.1016/j.jsgi.2006.04.005

Chan, W. Y., and Chen, D. L. (1992). Myometrial oxytocin receptors and prostaglandin in the parturition process in the rat. Biol. Reprod. 46, $58-64$.

Friebe-Hoffmann, U., Baston, D. M., Hoffmann, T. K., Chiao, J. P., and Rauk, P. N. (2007). The influence of interleukin-lbeta on oxytocin signalling in primary cells of human decidua. Regul. Pept. 142, 78-85. doi: 10.1016/j.regpep.2007.01.012

Fuentes, A., Spaziani, E. P., and O'Brien, W. F. (1996). The expression of cyclooxygenase-2 (COX-2) in amnion and decidua following spontaneous labor. Prostaglandins 52, 261-267.

Gibb, W. (1998). The role of prostaglandins in human parturition. Ann. Med. 30, 235-241.

Goldenberg, R. L., Culhane, J. F., Iams, J. D., and Romero, R. (2008). Epidemiology and causes of preterm birth. Lancet 371, 75-84. doi: 10.1016/S01406736(08)60074-4

Hansen, W. R., Keelan, J. A., Skinner, S. J., and Mitchell, M. D. (1999). Key enzymes of prostaglandin biosynthesis and metabolism. Coordinate regulation of expression by cytokines in gestational tissues: a review. Prostaglandins Other Lipid Mediat. 57, 243-257. 
Helliwell, R. J., Adams, L. F., and Mitchell, M. D. (2004). Prostaglandin synthases: recent developments and a novel hypothesis. Prostaglandins Leukot. Essent. Fatty Acids 70, 101-113. doi: 10.1016/j.plefa.2003.04.002

Ivanisevic, M., Djelmis, J., and Bukovic, D. (2001). Review on prostaglandin and oxytocin activity in preterm labor. Coll. Antropol. 25, 687-694.

Johnson, R. F., Mitchell, C. M., Giles, W. B., Walters, W. A., and Zakar, T. (2002). The in vivo control of prostaglandin $\mathrm{H}$ synthase- 2 messenger ribonucleic acid expression in the human amnion at parturition. J. Clin. Endocrinol. Metab. 87, 2816-2823. doi: 10.1210/jcem.87.6.8524

Kang, J., Chapdelaine, P., Laberge, P. Y., and Fortier, M. A. (2006). Functional characterization of prostaglandin transporter and terminal prostaglandin synthases during decidualization of human endometrial stromal cells. Hum. Reprod. 21, 592-599. doi: 10.1093/humrep/dei400

Kang, J., Chapdelaine, P., Parent, J., Madore, E., Laberge, P. Y., and Fortier, M. A. (2005). Expression of human prostaglandin transporter in the human endometrium across the menstrual cycle. J. Clin. Endocrinol. Metab. 90, 2308-2313. doi: 10.1210/jc.2004-1482

Lartey, J., Gampel, A., Pawade, J., Mellor, H., and Bernal, A. L. (2006). Expression of RND proteins in human myometrium. Biol. Reprod. 75, 452-461. doi: 10.1095/biolreprod.105.049130

Li, X. Q., Zhu, P., Myatt, L., and Sun, K. (2014). Roles of glucocorticoids in human parturition: a controversial fact? Placenta 35, 291-296. doi: 10.1016/j.placenta.2014.03.005

Lopez Bernal, A., Rivera, J., Europe-Finner, G. N., Phaneuf, S., and Asbóth, G. (1995). "Parturition: activation of stimulatory pathways or loss of uterine quiescence?" in Oxytocin: Cellular and MolecularApproaches, eds R. Ivell and J. Russell (London: Plenum Press), 435-451.

Lu, R., Kanai, N., Bao, Y., and Schuster, V. L. (1996). Cloning, in vitro expression, and tissue distribution of a human prostaglandin transporter cDNA(hPGT). J. Clin. Invest. 98, 1142-1149.

Mitchell, M. D., Flint, A. P., Bibby, J., Brunt, J., Arnold, J. M., Anderson, A. B., et al. (1977). Rapid increases in plasma prostaglandin concentrations after vaginal examination and amniotomy. Br. Med. J. 2, 1183-1185.

Myatt, L., and Sun, K. (2010). Role of fetal membranes in signaling of fetal maturation and parturition. Int. J. Dev. Biol. 54, 545-553. doi: 10.1387/ijdb.082771lm

Navitsky, J., Greene, J. F., and Curry, S. L. (2000). The onset of human labor: current theories. Prim. Care Update Ob Gyns 7, 197-199. doi: 10.1016/S1068607X(00)00046-9

Norwitz, E. R., Lopez Bernal, A., and Starkey, P. M. (1992). Tumor necrosis factoralpha selectively stimulates prostaglandin F2 alpha production by macrophages in human term decidua. Am. J. Obstet. Gynecol. 167, 815-820.

Olson, D. M., and Ammann, C. (2007). Role of the prostaglandins in labour and prostaglandin receptor inhibitors in the prevention of preterm labour. Front. Biosci. 12, 1329-1343. doi: 10.2741/2151

Osman, I., Young, A., Ledingham, M. A., Thomson, A. J., Jordan, F., Greer, I. A., et al. (2003). Leukocyte density and pro-inflammatory cytokine expression in human fetal membranes, decidua, cervix and myometrium before and during labour at term. Mol. Hum. Reprod. 9, 41-45. doi: 10.1093/molehr/gag001

Phillips, R. J., Al-Zamil, H., Hunt, L. P., Fortier, M. A., and Lopez Bernal, A. (2011). Genes for prostaglandin synthesis, transport and inactivation are differentially expressed in human uterine tissues, and the prostaglandin F synthase AKR1B1 is induced in myometrial cells by inflammatory cytokines. Mol. Hum. Reprod. 17, 1-13. doi: 10.1093/molehr/gaq057

Pont, J. N., McArdle, C. A., and Lopez Bernal, A. (2012). Oxytocin-stimulated NFAT transcriptional activation in human myometrial cells. Mol. Endocrinol. 26, 1743-1756. doi: 10.1210/me.2012-1057

Prince, A. L., Antony, K. M., Chu, D. M., and Aagaard, K. M. (2014). The microbiome, parturition, and timing of birth: more questions than answers. J. Reprod. Immunol. doi: 10.1016/j.jri.2014.03.006. [Epub ahead of print]

Romero, R., Mazor, M., Brandt, F., Sepulveda, W., Avila, C., Cotton, D. B., et al. (1992). Interleukin-1 alpha and interleukin-1 beta in preterm and term human parturition. Am. J. Reprod. Immunol. 27, 117-123.

Sadowsky, D. W., Adams, K. M., Gravett, M. G., Witkin, S. S., and Novy, M. J. (2006). Preterm labor is induced by intraamniotic infusions of interleukin-1beta and tumor necrosis factor-alpha but not by interleukin-6 or interleukin-8 in a nonhuman primate model. Am. J. Obstet. Gynecol. 195, 1578-1589. doi: 10.1016/j.ajog.2006.06.072

Schuster, V. L. (1998). Molecular mechanisms of prostaglandin transport. Annu. Rev. Physiol. 60, 221-242.

Sellers, S. M., Mitchell, M. D., Bibby, J. G., Anderson, A. B., and Turnbull, A. C. (1981). A comparison of plasma prostaglandin levels in term and preterm labour. Br. J. Obstet. Gynaecol. 88, 362-366.

Senior, J., Marshall, K., Sangha, R., and Clayton, J. K. (1993). In vitro characterization of prostanoid receptors on human myometrium at term pregnancy. Br. J. Pharmacol. 108, 501-506.

Slater, D., Dennes, W., Sawdy, R., Allport, V., and Bennett, P. (1999). Expression of cyclo-oxygenase types-1 and -2 in human fetal membranes throughout pregnancy. J. Mol. Endocrinol. 22, 125-130.

Stika, C. S., Gross, G. A., Leguizamon, G., Gerber, S., Levy, R., Mathur, A., et al. (2002). A prospective randomized safety trial of celecoxib for treatment of preterm labor. Am. J. Obstet. Gynecol. 187, 653-660. doi: 10.1067/mob.2002. 125281

Suzuki, T., Fujii, Y., Miyano, M., Chen, L. Y., Takahashi, T., and Watanabe, K. (1999). cDNA cloning, expression, and mutagenesis study of liver-type prostaglandin F synthase. J. Biol. Chem. 274, 241-248.

Watanabe, K. (2002). Prostaglandin F synthase. Prostaglandins Other Lipid Mediat. 68-69, 401-407. doi: 10.1016/S0090-6980(02)00044-8

Watanabe, K., Yoshida, R., Shimizu, T., and Hayaishi, O. (1985). Enzymatic formation of prostaglandin F2 alpha from prostaglandin H2 and D2. Purification and properties of prostaglandin F synthetase from bovine lung. J. Biol. Chem. 260, 7035-7041.

Weiss, G. (2000). Endocrinology of parturition. J. Clin. Endocrinol. Metab. 85, 4421-4425. doi: 10.1210/jcem.85.12.7074

Yuan, W., Duffner, A. M., Chen, L., Hunt, L. P., Sellers, S. M., and Bernal, A. L. (2010). Analysis of preterm deliveries below 35 weeks' gestation in a tertiary referral hospital in the UK. A case-control survey. BMC Res. Notes 3:119. doi: 10.1186/1756-0500-3-119

Zaga, V., Estrada-Gutierrez, G., Beltran-Montoya, J., Maida-Claros, R., LopezVancell, R., and Vadillo-Ortega, F. (2004). Secretions of interleukin-1beta and tumor necrosis factor alpha by whole fetal membranes depend on initial interactions of amnion or choriodecidua with lipopolysaccharides or group B streptococci. Biol. Reprod. 71, 1296-1302. doi: 10.1095/biolreprod.104. 028621

Zaga-Clavellina, V., Garcia-Lopez, G., Flores-Herrera, H., Espejel-Nunez, A., Flores-Pliego, A., Soriano-Becerril, D., et al. (2007). In vitro secretion profiles of interleukin (IL)-1beta, IL-6, IL-8, IL-10, and TNF alpha after selective infection with Escherichia coli in human fetal membranes. Reprod. Biol. Endocrinol. 5:46. doi: $10.1186 / 1477-7827-5-46$

Conflict of Interest Statement: Michel Fortier has a patent for methods for the regulation of the prostaglandin F synthase (PGFS) activity of AKR1B1 and uses thereof. The authors declare that the research was conducted in the absence of any commercial or financial relationships that could be construed as a potential conflict of interest.

Received: 15 May 2014; accepted: 01 July 2014; published online: 30 July 2014. Citation: Alzamil HA, Pawade J, Fortier MA and López Bernal A (2014) Expression of the prostaglandin F synthase AKR1B1 and the prostaglandin transporter SLCO2A1 in human fetal membranes in relation to spontaneous term and preterm labor. Front. Physiol. 5:272. doi: 10.3389/fphys.2014.00272

This article was submitted to Clinical and Translational Physiology, a section of the journal Frontiers in Physiology.

Copyright (c) 2014 Alzamil, Pawade, Fortier and López Bernal. This is an openaccess article distributed under the terms of the Creative Commons Attribution License (CC BY). The use, distribution or reproduction in other forums is permitted, provided the original author(s) or licensor are credited and that the original publication in this journal is cited, in accordance with accepted academic practice. No use, distribution or reproduction is permitted which does not comply with these terms. 